\title{
Synthesis and performance evaluation of silica-supported copper chromite catalyst for glycerol dehydration to acetol
}

\author{
S BASU, A K SEN* (1) and M MUKHERJEE \\ Department of Chemical Engineering, Birla Institute of Technology Mesra, Ranchi, Jharkhand, India \\ E-mail: akhilsen@bitmesra.ac.in; akhilsen@yahoo.co.in
}

MS received 10 May 2019; revised 16 June 2019; accepted 30 June 2019

\begin{abstract}
Sol-gel technique was used to prepare silica-supported copper chromite catalyst from acid hydrolysis of sodium silicate. The catalyst was characterized by BET surface area, FESEM, XRD, $\mathrm{H}_{2}-\mathrm{TPR}$ and pyridine adsorption by FTIR. The catalyst was activated in a hydrogen atmosphere based on $\mathrm{H}_{2}$-TPR result. The surface acidity of the catalyst was evaluated by $\mathrm{NH}_{3}$-TPD and pyridine adsorption. XRD result of reduced catalyst showed the presence of $\mathrm{Cu}^{0}, \mathrm{Cu}^{1+}$ and $\mathrm{Cr}_{2} \mathrm{O}_{3}$ in the catalyst. Glycerol dehydration was carried out at different temperature $\left(180{ }^{\circ} \mathrm{C}\right.$ to $\left.240{ }^{\circ} \mathrm{C}\right)$ from aqueous glycerol solution with the reduced catalyst in a batch reactor. The glycerol conversion was reached $100 \%$ with maximum acetol selectivity of $70 \%$ for highest Copper chromite loaded $(40 \mathrm{wt} \%)$ on silica at $220{ }^{\circ} \mathrm{C}$ in atmospheric pressure. The distilled liquid product was analyzed by high-performance liquid chromatography. Oxidized catalyst and spent catalyst showed lower glycerol conversion with low acetol selectivity than the reduced form of the catalyst. This is due to the cuprous ion in the reduced form of the catalyst, which acts as Lewis acid sites in glycerol dehydration.
\end{abstract}

Keywords. Glycerol; copper chromite; acetol; pyridine-FTIR; $\mathrm{H}_{2}$-TPR; XRD.

\section{Introduction}

Biodiesel has shown potentials to act as the supplement of fossil diesel since it is a renewable and environment-friendly source of energy. But the major obstruction to use biodiesel is the high cost of production. ${ }^{1}$ Biodiesel significantly reduces engine emissions such as sulfur dioxide (100\%), unburned hydrocarbons $(68 \%)$ and polycyclic aromatic hydrocarbons $(80-90 \%)^{2}$ To produce $9 \mathrm{~kg}$ of biodiesel, about $1 \mathrm{~kg}$ of crude glycerol is formed as a by-product. Most of the biodiesel producers refine glycerol for sale as a commodity in the glycerol market. Several steps (acid and alkali treatment followed by distillation) are used to purify glycerol from the crude solution to $80-85 \%$ glycerol. Further purification to produce pure glycerol increases the overall price, which is not costeffective. However, an increase in the production of biodiesel is expected to reduce the price of glycerol, and also, the glycerol conversion to other consumer products is much more desirable. The spectrum of glycerol utilization has also grown such that presently it has over 1500 known end uses. The conversion of

*For correspondence

Published online: 27 August 2019

Published online: 27 August 2019 glycerol to other value-added commodity products are mainly based on processes like heterogeneous catalysis of hydrogenolysis, dehydration, etherification, etc. $^{3-5}$ Mario and Pagliaro ${ }^{6}$ summarize twenty-two different possible ways to convert glycerol into valueadded products like polyhydroxylalkanoates, citricacid, hydrogen, 2'2-dimethyl-1'3-dioxolan-4-methylacetate, monoglyceride, etc.

Glycerol dehydration primarily results in two different products. One is acrolein, and the other is hydroxyacetone (HA) or acetol which can be further converted into 1,2 and 1,3-propanediol through hydrogenation. ${ }^{7,8}$ Acetol plays a very important role in organic synthesis and intermediates. Also, it is used in industries like food, dyes and additives. ${ }^{9}$ The price of acetol is high and it is produced industrially from petroleum resources. Crude petroleum reserves are depleting day by day and hence a bio-based source of acetol is an obvious choice of research. In the literature, several transition metal catalysts have been tested for glycerol dehydration. Copper is well known for the lower ability to cleave the $\mathrm{C}-\mathrm{C}$ bonds of a glycerol molecule, resulting in undesirable degradation products. ${ }^{10}$ Huang et al., ${ }^{11}$ have prepared silica-supported 
$\mathrm{CuO}$ catalyst by gel precipitation technique due to strong copper/support interaction, and this catalyst proves to be much more active. They have reported that the conversion of glycerol is $73 \%$. This is due to high copper dispersion and small metal particle size. Kim et al., ${ }^{12}$ have used chromium to promote the activity of copper. They have done co-precipitation of chromium with copper which dramatically increases the activity of glycerol, converts $87 \%$ to 1,2propanediol with $84 \%$ selectivity. Because of the synergistic effect of $\mathrm{Cu}$ and $\mathrm{Cr}$ the activity of copper chromite catalyst is higher than an individual catalyst. ${ }^{13,14}$ Copper increases the intrinsic catalyst activity but is easily sintered. In the catalyst, chromium acts as a stabiliser to reduce the sintering rate. Sato et al., ${ }^{15}$ have shown that basic support $(\mathrm{MgO}, \mathrm{CaO}, \mathrm{ZnO})$ effectively shows low acetol selectivity but acidic support $\left(\mathrm{SiO}_{2}, \mathrm{Al}_{2} \mathrm{O}_{3}, \mathrm{ZrO}_{2}, \mathrm{Fe}_{2} \mathrm{O}_{3}\right)$ effectively promotes acetol selectively. Copper chromite is one of the efficient catalysts for converting glycerol to acetol. ${ }^{16,17}$ In addition, the low oxidation state of copper species in the cubic spinal form is very important for a catalytic application. Vasiliadou and Lemonidou ${ }^{18}$ have used copper supported on mesoporous silica for glycerol hydrogenolysis reaction. They observed that strong deactivation for this catalyst is due to copper particle sintering and strongly adsorbed carbonaceous deposit in the mesoporous structures. Depending on the catalyst and the operating conditions, the reaction of glycerol hydrogenolysis proceeds through two mechanisms. ${ }^{9,19,20}$ In one of the mechanism, dehydration of glycerol to form acetol on acid sites was followed by hydrogenation step on metal sides. Another mechanism is where dehydrogenation of glycerol to glyceraldehydes over basic site was followed by dehydration to acetol and finally hydrogenation to propylene glycol. Since hydrogenation requires high hydrogen pressure so side reaction occurs to form several by-products including ethylene glycol, lactic acid, propionic acid, etc. ${ }^{9,21,22}$

In this study, acetol production was optimized with the help of silica-supported copper chromite catalyst. The catalyst was synthesized from acid hydrolysis of sodium silicate. The active component copper chromite was added during the synthesis of silica. The catalyst was activated in a hydrogen atmosphere before glycerol dehydration. The catalyst was characterized by BET surface area, FESEM, XRD, TGA, $\mathrm{H}_{2}$-TPR, $\mathrm{NH}_{3}$-TPD, pyridine FTIR. The reaction was carried out with different catalytic system by varying reaction conditions. Based on the reaction products a mechanism have been proposed for getting high selectivity of acetol.

\section{Experimental}

\subsection{Materials}

Glycerol (AR grade) was purchased from (Nice chemical Pvt. Ltd.) for dehydration studies. Acetol (Sigma-Aldrich) was used as a reference for HPLC calibration. Sodium silicate $\left(\mathrm{Na}_{2} \mathrm{SiO}_{3} .9 \mathrm{H}_{2} \mathrm{O}\right.$, Loba Chemie), Polyvinyl alcohol (PVA, Mol. wt. 85000-124000, S. D. Fine Chem. Ltd.) were used for silica support preparations. Phenol (AR grade) was used to increase the porosity of the silica matrix. The active compound copper chromite $\left(\mathrm{CuO} . \mathrm{CuCr}_{2} \mathrm{O}_{4}\right)$ was purchased from Spectrochem India.

\subsection{Catalyst preparation}

Silica supported copper chromite catalyst was prepared from acid hydrolysis of sodium silicate $\left(\mathrm{Na}_{2} \mathrm{SiO}_{3}\right)$ by sol-gel technique. ${ }^{23}$ Polyvinyl alcohol (PVA) was added as a stabilizer to get regular particle sizes. A small quantity of phenol was added to increase the porosity in the silica matrix. During hydrolysis stoichiometric amount of copper, chromite was added to incorporate into the silica matrix. A typical reaction scheme was as follows. $2 \mathrm{gm}$ of PVA was dissolved in $100 \mathrm{~mL}$ of distilled water and the required quantity of sodium silicate solution was added to it. The mixture was heated till $60{ }^{\circ} \mathrm{C}$, under agitated condition using magnetic stirrer and $10 \mathrm{gm}$ of phenol was added into the mixture. $2 \mathrm{~N}$ $\mathrm{HCl}$ solution was added dropwise into the mixture in heating and stirring condition to make the solution acidic. The addition of acid was continued up to initiation of cloud formation. Then desired amount of copper chromite powder (pass through 75 micron mesh size) was added into the solution. The $\mathrm{pH}$ of the mixture was adjusted to 1-2 by the addition of $2 \mathrm{~N} \mathrm{HCl}$ solution till the end. The heating and stirring were continued for another $2 \mathrm{~h}$. The reaction mixture was left for $24 \mathrm{~h}$. Then the precipitate was filtered and washed with distilled water several times until the removal of free acid. The precipitate was dried in an air oven at $100{ }^{\circ} \mathrm{C}$ until constant weight. Then it was grounded and calcined in a muffle furnace at $500{ }^{\circ} \mathrm{C}$ for $4 \mathrm{~h}$. The catalyst was activated in a tubular furnace at $350{ }^{\circ} \mathrm{C}$ for $4 \mathrm{~h}$ in a hydrogen atmosphere. The yield of the blank silica was $10 \mathrm{~g}$ for the typical compositions and the loading level was calculated based on the atomic weight $\%$ of copper as per molecular formula $\left(\mathrm{CuO} . \mathrm{CuCr}_{2} \mathrm{O}_{4}\right)$ provided by the supplier to maintain the $\left(\mathrm{Cu}: \mathrm{SiO}_{2}\right)$ mass ratio. The composition of the different catalyst system and nomenclature were given in Table 1.

\subsection{Characterization of catalyst}

Nitrogen adsorption-desorption isotherms measured at $77 \mathrm{~K}$ with a multipoint method using Quantachrome Nova touch surface area and a pore size analyzer. The catalyst samples were degassed at $200{ }^{\circ} \mathrm{C}$ for $4 \mathrm{~h}$ under vacuum. 
Table 1. Compositions and nomenclature of the catalyst.

\begin{tabular}{ccccc}
\hline Serial No. & Sodium silicate $(\mathrm{g})$ & Copper Chromite $(\mathrm{g})$ & $\begin{array}{c}\mathrm{Cu}: \mathrm{SiO}_{2} \\
\text { Mass ratio }\end{array}$ & Nomenclature \\
\hline 1 & 47 & - & $0: 10$ & $\mathrm{SiO}_{2}$ \\
2 & 42.6 & 2.4 & $1: 9$ & $\mathrm{SiCuCr}_{0}$ \\
3 & 37.8 & 4.8 & $2: 8$ & $\mathrm{SiCuCr} 20$ \\
4 & 33.1 & 7.4 & $3: 7$ & $\mathrm{SiCuCr} 30$ \\
5 & 28.4 & 9.8 & $4: 6$ & $\mathrm{SiCuCr} 40$
\end{tabular}

The images of surface morphology and the elemental mapping of the catalyst were determined by Field Emission Scanning Electron Microscopy (FESEM) using Sigma 300 with EDAX (Ametek) at different magnification level. The powder was gold-coated before FESEM studies and elemental mapping.

X-ray diffraction (XRD) patterns of catalysts were obtained at room temperature using a Rigaku, Japan Diffractometer (Smart Lab, $9 \mathrm{~kW}$ ) equipped with a vertical goniometer. The scans were collected in the range of $2 \theta=10-80 \quad$ using copper $(\mathrm{CuK} \alpha 1$ radiation, $\lambda=1.54056 \mathrm{~nm}, 45 \mathrm{KV}$ and $200 \mathrm{~mA}$ ) at the scanning speed of $0.05^{\circ}(2 \theta) / \mathrm{s}$. The diffractograms of the experiment were compared with the ICDD powder diffraction file database.

The thermal stabilities of the catalysts were determined by thermogravimetric analysis (TGA) using a SHIMADZU thermogravimetric analyzer DTG 60 model. The catalyst sample was heated in a platinum pan from room temperature to $800{ }^{\circ} \mathrm{C}$ at a heating rate of $10{ }^{\circ} \mathrm{C} / \mathrm{min}$ under nitrogen atmosphere.

Temperature programmed reduction $\left(\mathrm{H}_{2}\right.$-TPR) of silicasupported copper chromite catalyst was performed in Quantachrome ChemBet Pulsur chemisorption flow analyzer equipped with thermal conductivity detector (TCD). The reduction experiment was carried out in a U-shaped quartz reactor. Exactly $0.1 \mathrm{~g}$ of powdered sample was placed in the reactor. Prior to the reduction, the catalyst was pre-treated to $200{ }^{\circ} \mathrm{C}$ at the heating rate of $10{ }^{\circ} \mathrm{C} / \mathrm{min}$ in helium gas flow of $80 \mathrm{~mL} / \mathrm{min}$. After $30 \mathrm{~min}$ at $200{ }^{\circ} \mathrm{C}$ the catalyst was cooled down to room temperature in Helium (He) atmosphere. For reduction, a reducing gas $\left(5 \% \mathrm{H}_{2}\right.$ in Ar) was used at the flow rate of $80 \mathrm{~mL} / \mathrm{min}$. The temperature was gradually increased from ambient temperature to $750{ }^{\circ} \mathrm{C}$ at the heating rate of $10{ }^{\circ} \mathrm{C} / \mathrm{min}$. $\mathrm{H}_{2}$ consumption was monitored by the thermal conductivity detector (TCD) continuously.

To determine the number of acid sites of the catalyst ${ }^{\text {* }}$ ammonia $\left(\mathrm{NH}_{3}\right)$ temperature-programmed desorption (TPD) was performed in the above instrument. Before carrying out the TPD experiment of the catalyst, about $0.1 \mathrm{~g}$ of sample was pre-treated in Helium flow $(80 \mathrm{~mL} / \mathrm{min})$ at $200{ }^{\circ} \mathrm{C}$ at heating rate $10 \% \mathrm{~min}$ for the $30 \mathrm{~min}$. After cooling the catalyst in a helium atmosphere to $40{ }^{\circ} \mathrm{C}$ the helium ammonia gas mixture (5\% $\mathrm{NH}_{3}-95 \% \mathrm{He}$ ) flow was started and continued up to $30 \mathrm{~min}$. Then pure helium gas flow was started at room temperature for $30 \mathrm{~min}$ to remove any ammonia gas present in the system. Thermal treatment was performed and the temperature rose from $50{ }^{\circ} \mathrm{C}$ to $750{ }^{\circ} \mathrm{C}$ at $10 \% \mathrm{~min}$. In order to determine the acidity of the catalyst from $\mathrm{NH}_{3}$-TPD profiles areas under the curves were integrated by Gaussian deconvolution of the peaks and amount of acidity was expressed in micromoles per gram of the catalyst.

To determine the nature of acid and strength of acid sites pyridine adsorbed FTIR was done (Shimadzu Corpn., Japan; IR-Prestige 21). Before recording analysis, all reduced catalyst samples and pyridine were taken in a separate Petri dish, and kept in a vacuum oven $(500 \mathrm{~mm}$ $\mathrm{Hg}$ ) overnight to reach equilibrium. Before analysis, the samples were taken out from vacuum oven and the spectrums were recorded in DRS mode.

\subsection{Catalytic performance evaluation}

Dehydration of glycerol was carried out in a stainless steel batch reactor of $500 \mathrm{~mL}$ capacity (Amar Equipment, India) equipped with an electrical temperature controller and a mechanical stirrer. The reaction was carried out at various temperatures at atmospheric pressure. $20 \%$ aqueous glycerol solution was fed into the reactor vessel and $1 \mathrm{~g}$ reduced catalyst was added into the reactor. ${ }^{24}$ The glycerol and catalyst mixture was agitated at a speed of $700 \mathrm{rpm}$ to create a slurry reaction mixture. The distilled product was condensed by passing the vapour through a water condenser in which chilled water at $10{ }^{\circ} \mathrm{C}$ was circulated. Initial fraction (from room temperature to $100{ }^{\circ} \mathrm{C}$ ) of the distilled product was discarded as it is considered that the dehydration reaction starts above $100{ }^{\circ} \mathrm{C}$. The distilled product was collected after reaching the desired temperature $\left(180{ }^{\circ} \mathrm{C}, 200{ }^{\circ} \mathrm{C}, 220^{\circ} \mathrm{C}, 240^{\circ} \mathrm{C}\right)$ and analyzed by HPLC (high-pressure liquid chromatography). The reaction was continued up to $3 \mathrm{~h}$ at the reaction temperature. The distilled products were collected, sealed and stored for analysis. The residue in the reactor was collected and after weighing it was washed with methanol followed by filtration and air drying to separate the spent catalyst.

\subsection{HPLC analysis of distillates}

To quantify the products obtained from the catalytic dehydration of glycerol high-performance liquid 
chromatography (HPLC) from waters was used. ${ }^{25}$ The HPLC system was equipped with two pumps (waters 515 HPLC pump) and UV/Vis detector (water 2487 dual $\lambda$ absorbance detector). Acetonitrile and water mixture were used as the mobile phase at the volume ratio 40:60 in isocratic mode. The flow rate of the mobile phase was fixed at $0.1 \mathrm{~mL} / \mathrm{min}$. C-18 column was used in this study. ${ }^{26}$ The injection volume was $20 \mu \mathrm{L}$. The terms of conversion and selectivity were defined by the following expression.

Glycerol conversion \%

Initial mass of glycerol and catalyst - Residue after reaction Initial mass of glycerol

$\times 100$

The selectivity of the products (acetol, acetaldehyde and acetic acid, etc.) was calculated based on the formula:

Product selectivity $\%=\frac{\text { Mass of specific product }}{\text { Mass of all liquid products }} \times 100$

\section{Results and Discussion}

Silica-supported copper chromite catalyst are prepared by acid hydrolysis of sodium silicate and copper chromite is added during the preparation of silica. The precipitated material is washed and dried in air oven followed by calcination at $500{ }^{\circ} \mathrm{C}$ for $4 \mathrm{~h}$ in a muffle furnace. The properties of the synthesized catalyst are evaluated by BET specific surface area, FESEM, XRD, TGA, $\mathrm{H}_{2}-\mathrm{TPR}, \mathrm{NH}_{3}$-TPD and pyridine FTIR.

\subsection{Catalyst characterization results}

3.1a BET surface area: The surface area and pore volume of silica-supported copper chromite are given in Table 2. The surface area and pore volume are highest for $30 \mathrm{wt} \%$ copper chromite containing silica followed by $\mathrm{SiCuCr} 40$. The $\mathrm{BJH}$ pore diameter is similar for $30 \mathrm{wt} \%$ and $40 \mathrm{wt} \%$ sample. Literature reported that the catalyst prepared by precipitation gel technique is stable due to strong interaction with the silica matrix. ${ }^{11,27}$ Vasiliadu et al., ${ }^{18}$ have reported that the activity of the highly dispersed copper in a mesoporous silica-based catalyst for the hydrogenolysis of glycerol reduces due to the strong adsorption of carbonaceous material inside the pore structure.

\section{1b Field emission scanning electron microscope} (FESEM): FESEM micrographs of the copper chromite samples at $25 \mathrm{~K}$ magnification are shown in Figure 1. Catalysts are gold-coated for FESEM studies. The images show that the powders catalysts are irregular in shape and $\mathrm{SiCuCr} 40$ catalyst is different from others. This may be due to the higher loading of copper chromite where the proportion of silica reduces in the silica matrix, which results in a reduction of the probability of condensation between silica powders.

\section{1c EDX (energy dispersive $X$-ray} spectroscopy): Figure 2 is the elemental mapping of $\mathrm{SiCuCr} 20, \mathrm{SiCuCr} 30$ and SiCuCr40. This shows copper and chromium atoms are evenly distributed throughout the silica matrix. Table 3 is the EDX analysis of silicasupported copper chromite catalyst. The atomic per cent of copper and chromium is increasing order as the doping level increases in the silica support. EDX study is mainly the surface concentration of atoms, which are responsible for catalytic purposes. As expected $40 \mathrm{wt} \%$ samples show the highest content of copper and chromium. All the samples contain sodium ion which is common for precipitated silica samples. Kinage et al., ${ }^{28}$ has reported that $5 \mathrm{wt} \%$ of sodium loaded in metal oxide greatly enhances the acetol selectivity in glycerol conversion.

3.1d Powder X-ray diffraction (XRD): Figure 3 shows the XRD diffraction of calcined silicasupported copper chromite catalyst. A broad and diffuse peak is observed at $20^{\circ}$ in lower loading copper chromite as compared to higher ones. This peak is attributed to $\mathrm{SiO}_{2}$. This is due to the diffraction of the amorphous nature of the silica. The strong crystalline peak of silica is observed at $2 \theta=31.9$ (ICDD\# 89-1666) at a lower level of loading which reduces at higher catalyst loading. ${ }^{29}$ The calcined samples

Table 2. Surface area and pore volume of silica-supported copper chromite.

\begin{tabular}{lcccc}
\hline Sample & BET surface area $\left(\mathrm{m}^{2} / \mathrm{g}\right)$ & BJH Surface area $\left(\mathrm{m}^{2} / \mathrm{g}\right)$ & Pore volume $\mathrm{V}_{\mathrm{p}}\left(\mathrm{cm}^{3} / \mathrm{g}\right)$ & Pore diameter $\mathrm{D}_{\mathrm{p}}(\mathrm{nm})$ \\
\hline $\mathrm{SiCuCr} 10$ & 35.99 & 16.36 & 0.088 & 3.6 \\
$\mathrm{SiCuCr} 20$ & 76.54 & 43.14 & 0.36 & 3.6 \\
$\mathrm{SiCuCr30}$ & 144.91 & 106.52 & 0.53 & 14.2 \\
$\mathrm{SiCuCr} 40$ & 96.32 & 65.71 & 0.45 & 14.3 \\
\hline
\end{tabular}



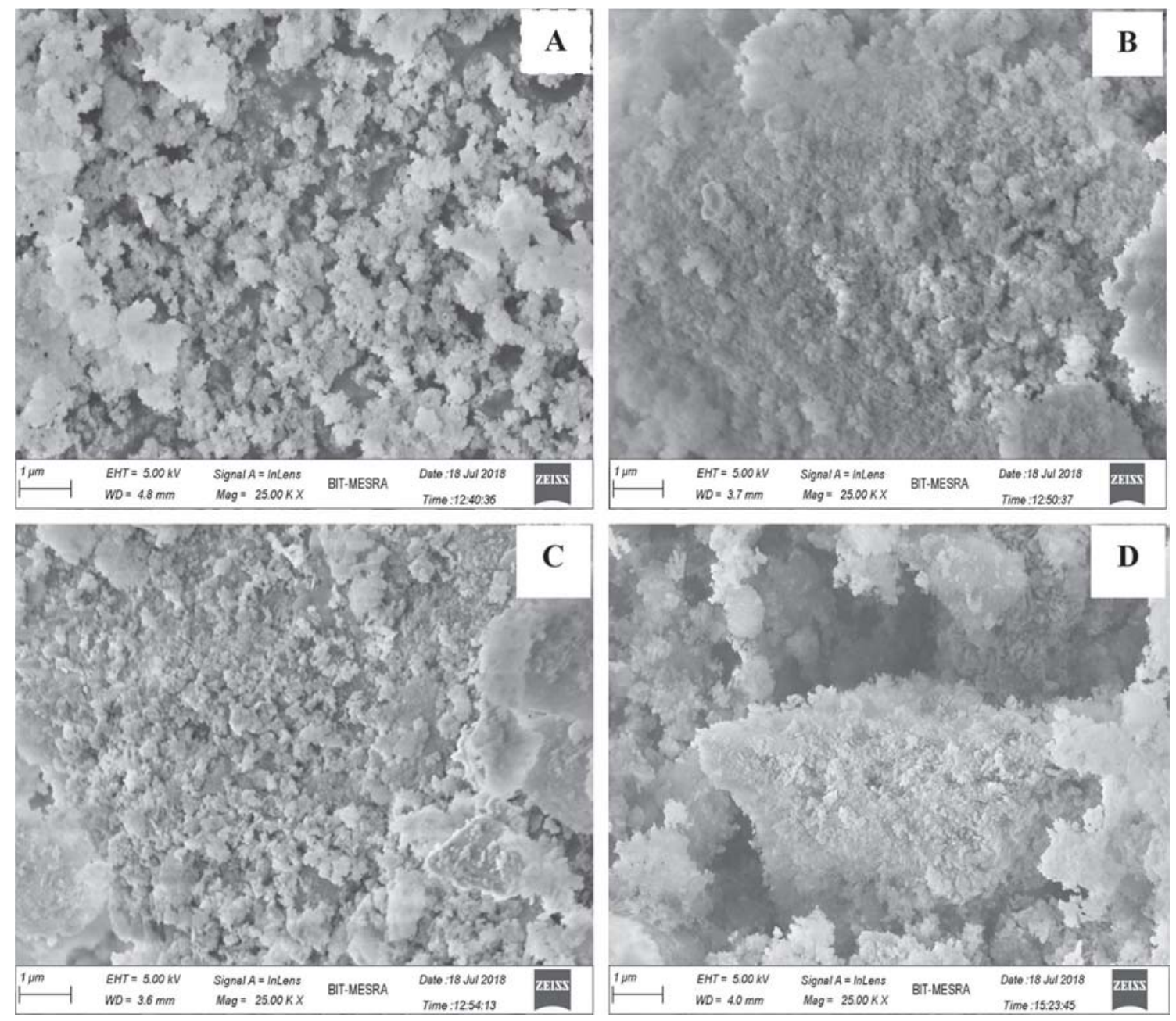

Figure 1. FESEM images of (A) SiCuCr10, (B) SiCuCr20, (C) SiCuCr30 and (D) SiCuCr40 catalyst at $25 \mathrm{~K}$ magnification.

show peaks at 35.5 and 37.5 which are the mixture of the monoclinic structure of $\mathrm{CuO}$ (ICDD\#89-5899) and tetragonal spinel structure of $\mathrm{CuCr}_{2} \mathrm{O}_{4}$ (ICDD\#210874) in which spinel proportion is more. ${ }^{30,31}$ The tetragonal spinel structure of copper chromite contains copper and chromium atoms placed on the tetrahedral and octahedral spaces. ${ }^{32}$

Figure 4 shows the XRD diffraction of the reduced form of silica-supported copper chromite catalyst. After reduction, the diffraction peak changes position indicating the change in compositions. In the reduced sample, the monoclinic structure of $\mathrm{CuO}$ and tetragonal spinal $\mathrm{CuCr}_{2} \mathrm{O}_{4}$ structure reduces and a new phase for metallic cubic $\mathrm{Cu}(2 \theta=43.4$ and 50.1) (ICDD\# 89-2838), cubic $\mathrm{Cu}_{2} \mathrm{O}(2 \theta=36.4$ and 65.25) (ICDD\# 78-2076) and rhombohedral $\mathrm{Cr}_{2} \mathrm{O}_{3}(2 \theta=24.4$ and 33.5) (ICDD\# 84-1616) are observed. The possible reaction scheme is as follows

$\mathrm{CuO} . \mathrm{CuCr}_{2} \mathrm{O}_{4} \stackrel{\mathrm{H}_{2}}{\longrightarrow} \mathrm{Cu}+\mathrm{Cu}_{2} \mathrm{O}+\mathrm{Cr}_{2} \mathrm{O}_{3}+\mathrm{H}_{2} \mathrm{O}$
Plyasova et al., ${ }^{33}$ has reported that the copper chromite reduces into the $\mathrm{Cu}^{0}$ and $\mathrm{Cu}^{+1}$ and $\mathrm{Cr}_{2} \mathrm{O}_{3}$ in a hydrogen atmosphere. The crystallite size of the $\mathrm{CuCr}_{2} \mathrm{O}_{4}, \mathrm{CuO}, \mathrm{Cu}_{2} \mathrm{O}, \mathrm{Cr}_{2} \mathrm{O}_{3}$ and $\mathrm{Cu}$ are calculated by full-width at half maximum (FWHM) from the values of diffraction peaks, respectively by Scherrer equation, $\mathrm{L}=\frac{\mathrm{K} \lambda}{\beta \operatorname{Cos} \theta}$ where $\mathrm{L}$ is the crystallite size, $\mathrm{K}$ is the Scherrer constant (0.89), $\lambda$ is the wavelength of radiation in radiant, $\theta$ is the Braggs diffraction angle, $\beta$ is the FWHM. The crystallite sizes of calcined and reduced catalysts are tabulated in Table 4 and Table 5 .

The diffraction peaks for reduced SiCuCr10 sample is very weak due to the low amount of copper chromite present in the silica matrix and is not shown in the reduced catalyst.

3.1e Thermo gravimetric analysis (TGA): Figure 5 is the TGA curve of silica-supported copper chromite catalyst. $10 \mathrm{wt} \%$ and $20 \mathrm{wt} \%$ copper chromite loaded samples shows nearly $10 \mathrm{wt} \%$ of weight loss below 

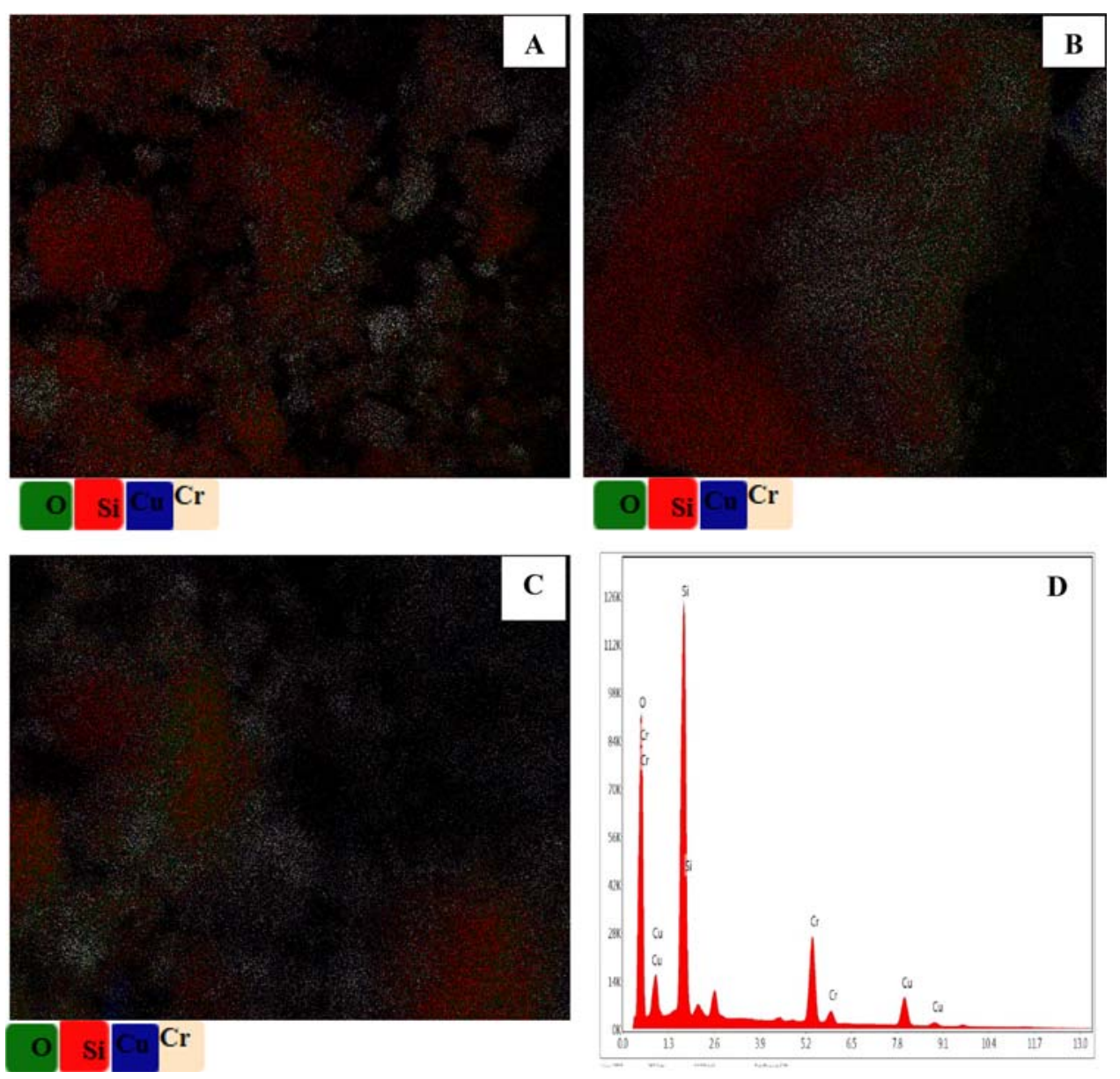

Figure 2. Elemental mapping of A) SiCuCr20, B) SiCuCr30, C) SiCuCr40 and D) EDX of SiCuCr40 catalyst in FESEM.

Table 3. EDX analysis of copper chromite containing silica.

\begin{tabular}{lccccc}
\hline & \multicolumn{5}{c}{ Atomic Weight \% } \\
\cline { 2 - 6 } Sample & $\mathrm{Cu}$ & $\mathrm{Cr}$ & $\mathrm{Si}$ & $\mathrm{O}$ & $\mathrm{Na}$ \\
\hline SiCuCr10 & 0.37 & 0.34 & 23.83 & 60.37 & 9.42 \\
SiCuCr20 & 1.62 & 2.70 & 23.02 & 60.11 & 8.55 \\
SiCuCr30 & 3.38 & 5.77 & 18.27 & 58.23 & 6.79 \\
SiCuCr40 & 5.51 & 9.60 & 15.55 & 54.94 & 8.60 \\
\hline
\end{tabular}

$100{ }^{\circ} \mathrm{C}$. This is due to adsorbed moisture by the silica samples. SiCuCr40 sample does not show any moisture adsorption as the silica proportion is less in the sample and the sample shows a low amount of weight loss (nearly $4 \mathrm{wt} \%$ ) up to $700{ }^{\circ} \mathrm{C} .{ }^{34}$ The residue at $700{ }^{\circ} \mathrm{C}$ is highest for $40 \mathrm{wt} \%$ loading and it reduces as the loading decreases. This is expected as the copper chromite is stable at high temperature and the weight loss takes place from the condensation of the silica matrix.

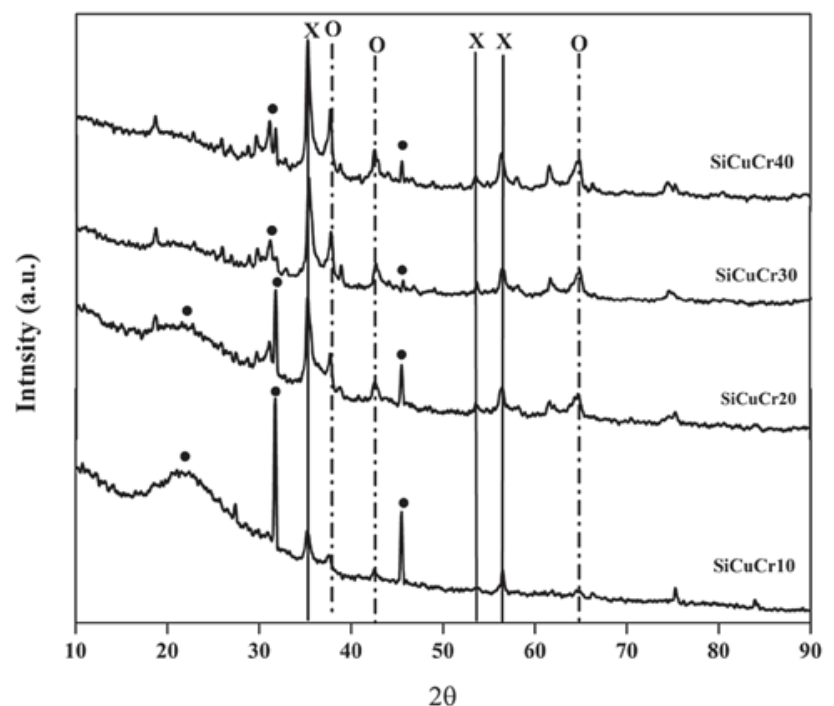

Figure 3. XRD patterns of calcined catalysts at different loading. (X) Monoclinic $\mathrm{CuO},(\mathrm{O})$ Tetragonal spinal $\mathrm{CuCr}_{2}$ $\mathrm{O}_{4},(\bigcirc)$ Silica.

3.1f Hydrogen temperature programmed reduction $\left(H_{2}-T P R\right)$ : Dehydration of glycerol takes place in the presence of an acidic catalyst. Literature reported 


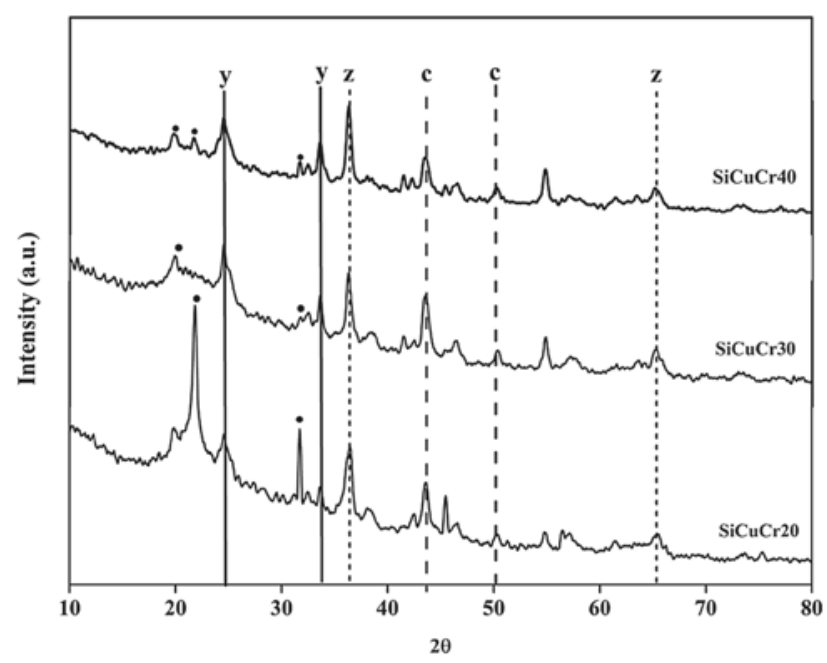

Figure 4. XRD patterns of reduced catalysts at different loading. (c) Cubic $\mathrm{Cu}$, (y) Rhembohedral $\mathrm{Cr}_{2} \mathrm{O}_{3}$, (z) Cubic $\mathrm{Cu}_{2} \mathrm{O},(\bullet)$ Silica.

that copper chromite is an effective catalyst for glycerol dehydration. Pre-reduced copper-based catalyst is an indispensable part of the glycerol hydrogenolysis. To have high activity, reduction conditions would have a great influence on catalytic performance. The TPR patterns of the calcined catalysts are shown in Figure 6. No peak is observed for $10 \mathrm{wt} \%$ loading catalyst (SiCuCr10) but for $20 \mathrm{wt} \%$ loaded sample (SiCuCr20) shows hump above $250{ }^{\circ} \mathrm{C}$ and is continued to $550{ }^{\circ} \mathrm{C}$ temperature. That means some amount of hydrogen has been consumed above $250{ }^{\circ} \mathrm{C}$. Similarly, for $\mathrm{SiCuCu} 30$ catalyst, the hydrogen consumption started above $250{ }^{\circ} \mathrm{C}$ and a broad peak near $450{ }^{\circ} \mathrm{C}$ is

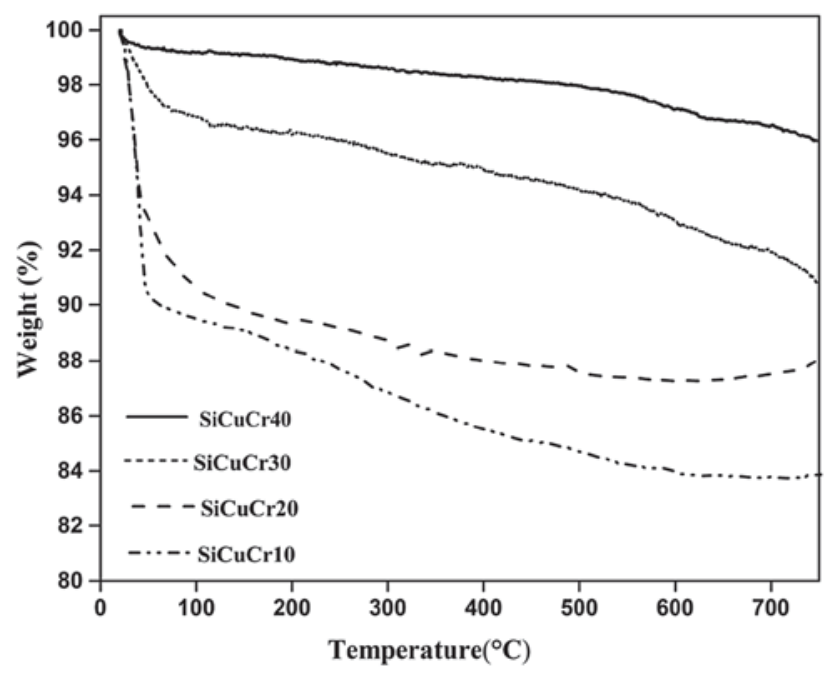

Figure 5. TGA curve for silica-supported copper chromite catalyst.

observed. In the case of $\mathrm{SiCuCr} 40$, the hydrogen consumption started above $250{ }^{\circ} \mathrm{C}$ with a peak value of $320{ }^{\circ} \mathrm{C}$ for $1^{\text {st }}$ peak and $500{ }^{\circ} \mathrm{C}$ for the second peak. The different peak position may be due to the size of the $\mathrm{CuO}$ species in the matrix. The surface $\mathrm{CuO}$ is more easily reducible than the bulk. XRD analysis of $30 \mathrm{wt} \%$ and $40 \mathrm{wt} \%$ sample (Table 5) supports the formation of $\mathrm{Cu}^{0}, \mathrm{Cu}^{1+}$ and $\mathrm{Cr}_{2} \mathrm{O}_{3}$. The change of catalytic phase $\mathrm{Cu}^{2+}$ to $\mathrm{Cu}^{+1}$ has a great influence on glycerol dehydration.

Luo et al., ${ }^{35}$ proposed that the metallic copper is primarily responsible for the activation of hydrogenation while $\mathrm{Cu}^{+}$is for dehydration due to its presence of Lewis acid sites. ${ }^{36-38}$ Ten dam and

Table 4. Crystallite size calculated from XRD data for calcined catalyst.

\begin{tabular}{lcccllll}
\hline & \multicolumn{3}{c}{$\mathrm{CuO}(\mathrm{nm})$} & & \multicolumn{3}{c}{$\mathrm{CuCr}_{2} \mathrm{O}_{4}(\mathrm{~nm})$} \\
\cline { 2 - 4 } \cline { 7 - 8 } Sample & $2 \theta=35.6$ & $2 \theta=53.64$ & $2 \theta=56.44$ & & $2 \theta=37.5$ & $2 \theta=42.2$ & $2 \theta=64.72$ \\
\hline SiCuCr10 & 12.78 & - & 12.03 & & - & 16.83 & - \\
SiCuCr20 & 16.44 & 25.61 & 8.83 & & 10.8 & 19.55 & 7.74 \\
SiCuCr30 & 22.41 & 16.61 & 9.09 & & 20.45 & 14.48 & 7.35 \\
SiCuCr40 & 23.44 & 14.24 & 10.03 & & 24.54 & 15.96 & 8.07 \\
\hline
\end{tabular}

Table 5. Crystallize size calculated from XRD data for reduced catalyst.

\begin{tabular}{lcccccccc}
\hline & \multicolumn{2}{c}{$\mathrm{Cu}(\mathrm{nm})$} & & \multicolumn{2}{c}{$\mathrm{Cu}_{2} \mathrm{O}(\mathrm{nm})$} & & \multicolumn{2}{c}{$\mathrm{Cr}_{2} \mathrm{O}_{3}(\mathrm{~nm})$} \\
\cline { 2 - 3 } \cline { 8 - 9 } Sample & $2 \theta=43.4$ & $2 \theta=50.1$ & & $2 \theta=36.4$ & $2 \theta=65.25$ & & $2 \theta=24.4$ & $2 \theta=33.5$ \\
\hline SiCuCr20 & 17.24 & - & & 14.99 & 1.01 & & 5.35 & 37.06 \\
SiCuCr30 & 13.58 & 23 & & 17.03 & 5.38 & & 3.3 & 33.36 \\
SiCuCr40 & 12.8 & 23.54 & & 16.94 & 3.7 & & 8.96 & 20.12 \\
\hline
\end{tabular}




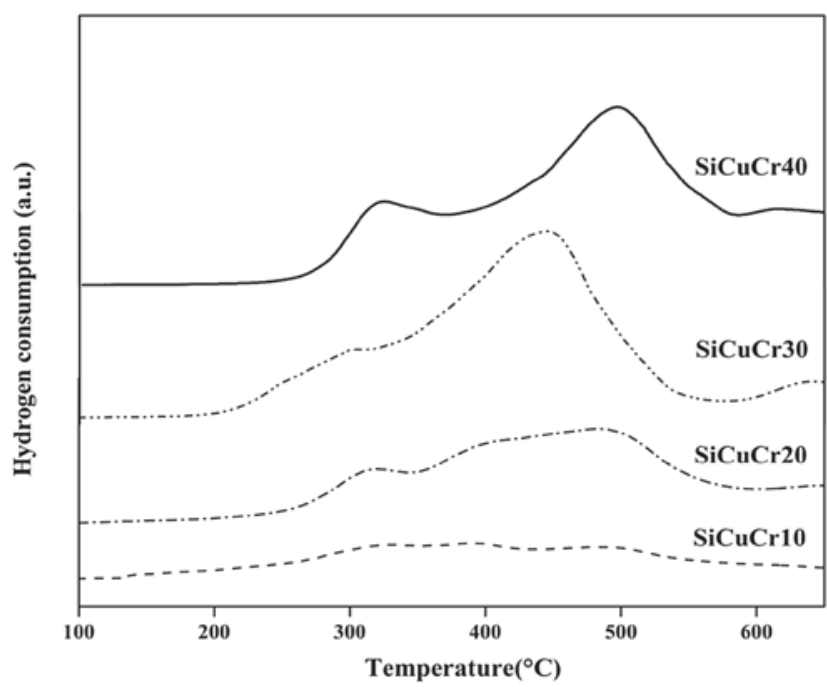

Figure 6. Temperature Programmed Reduction (TPR) profile for silica-supported copper chromite catalyst.

Hanefeld ${ }^{39}$ have discussed the dehydration mechanism of vicinal alcohol (Scheme 1). A Bronsted acid will help in the elimination of secondary alcohol which is subsequently dehydrated to acrolein (Scheme 2). Lewis acid more easily coordinates with primary alcohol which is easily accessible by the catalyst sites. This will lead to the formation of hydroxyacetone (HA) or acetol. Vasiliadou et al., ${ }^{18}$ have mentioned about the strong adsorption of glycerol on copper via its terminal $\mathrm{C}-\mathrm{O}$ bond, and the fact that it is not affected by the presence or absence of solvent. Based on the above discussion we are proposing that $\mathrm{Cu}_{2} \mathrm{O}$ is the active form of the catalyst, which acts as Lewis acid, and will produce acetol in glycerol dehydration reaction. Hence, we have decided to reduce the catalyst at $350{ }^{\circ} \mathrm{C}$ for the $4 \mathrm{~h}$ in hydrogen atmosphere.

3.1g Ammonia temperature programmed desorption $\left(\mathrm{NH}_{3}-\mathrm{TPD}\right)$ : Dehydration of glycerol is greatly influenced by acidic catalyst/support. To determine the acidic properties of catalyst towards the formation of a dehydration product, $\mathrm{NH}_{3}$-TPD (Ammonia
Temperature programmed desorption) is carried out (Figure 7). It investigates the amount of acid sites and the strength of acid distribution. In the $\mathrm{NH}_{3}$-TPD experiment, ammonia is adsorbed on acid sites of catalyst due to its basic nature. The maximum temperature in temperature versus TCD signal plot gives information of acidity of the catalyst and area under the desorption peak indicates acidic strength of the catalyst. ${ }^{40}$ There are three ranges of ammonia desorption peak: weak, intermediate and strong. ${ }^{22}$ It is said that if the area under the desorption curve is large then acid sites of the catalyst is higher in that region. Strength of the solid acid sites within TPD profile can be classified by $\mathrm{NH}_{3}$ desorption temperature ranges from $100-200{ }^{\circ} \mathrm{C}$ as weak ${ }^{\circ} 250-400{ }^{\circ} \mathrm{C}$ as moderate and $400-650{ }^{\circ} \mathrm{C}$ as strong.

The $\mathrm{SiCuCr} 20$ showed a peak at $120{ }^{\circ} \mathrm{C}$ indicating the presence of weak acid sites $\left(164 \mu \mathrm{mol} . \mathrm{g}^{-1}\right)$. This range of peak corresponds to weak acid sites for a surface hydroxyl group. ${ }^{40}$ The concentration of these sites is not important catalytically. While $\mathrm{SiCuCr} 30$ does not show any distinct peak but a hump at $150{ }^{\circ} \mathrm{C}$ in the low region with acidity $127 \mu \mathrm{mol} . \mathrm{g}^{-1}$ and $2^{\text {nd }}$ peak at $320{ }^{\circ} \mathrm{C}$ in the moderate region with surface acidity $234 \mu \mathrm{mol} . \mathrm{g}^{-1}$. This peak is closely related to surface acid properties. SiCuCr40 shows a broad peak at $583{ }^{\circ} \mathrm{C}$ but it starts above $150{ }^{\circ} \mathrm{C}$. The cumulative surface acidity for $\mathrm{SiCuCr} 40$ is $1250 \mu \mathrm{mol} . \mathrm{g}^{-1}$. Higher surface acidity for the catalyst is very much influential for catalyzing the glycerol dehydration to acetol. The nature of the surface acidity Bronsted/or Lewis acid sites is not distinct from the $\mathrm{NH}_{3}$-TPD studies. This may be due to the dry state adsorption of $\mathrm{NH}_{3}$ gas on catalyst surface at a higher temperature. To get more information about acidic sites, pyridine adsorption study by FTIR is carried out.

3.1h Pyridine adsorption by FTIR: The nature of acidic Brønsted/Lewis sites of Silica supported copper chromite is characterized by Pyridine adsorbed FTIR

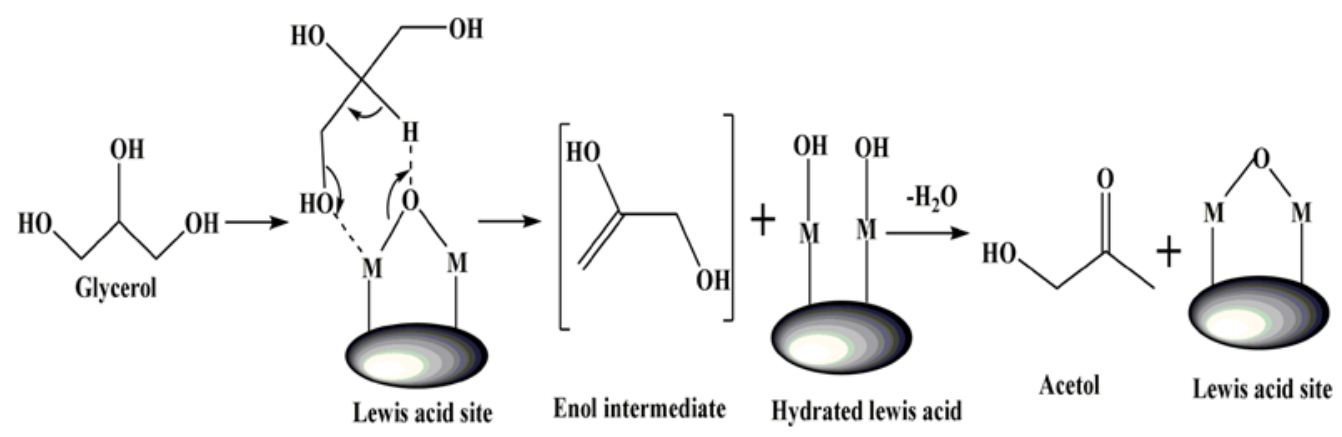

Scheme 1. Reaction mechanism on catalyst surface. 


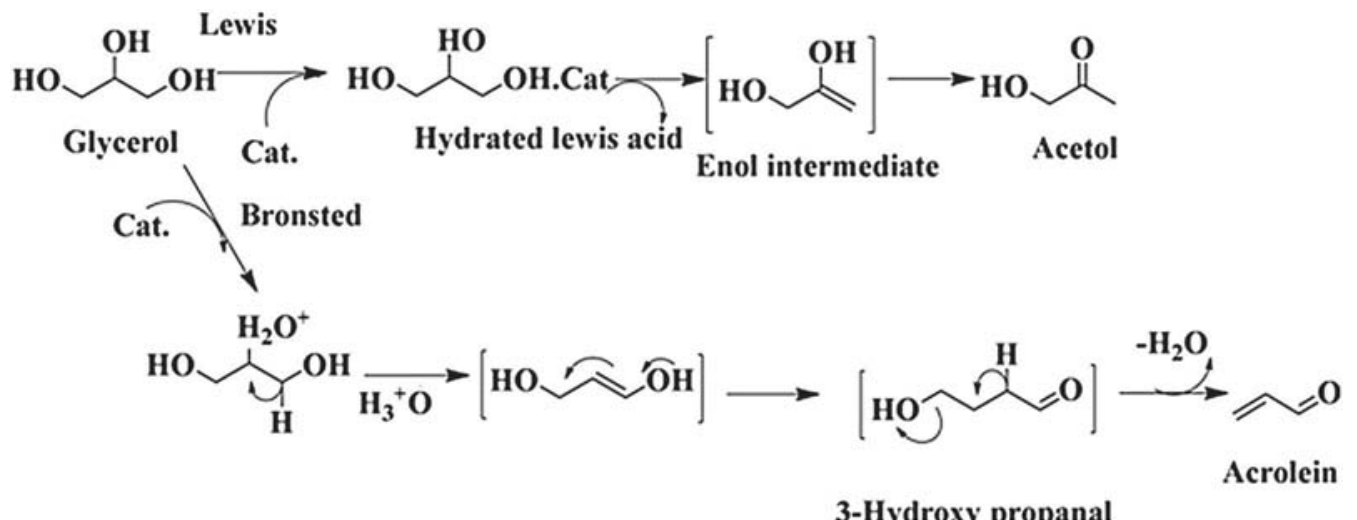

Scheme 2. Reaction scheme for dehydration of glycerol.

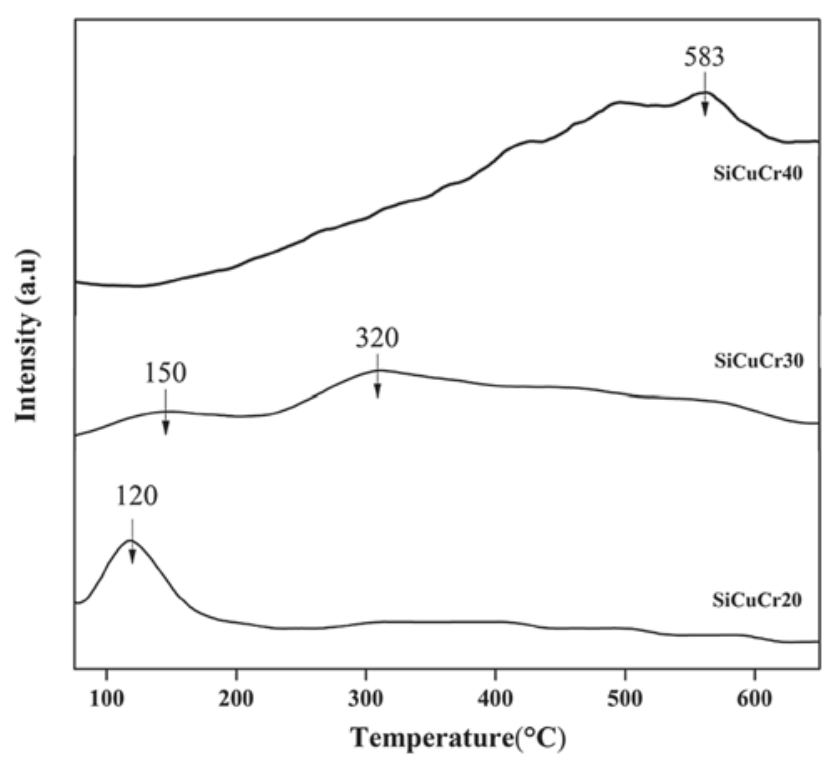

Figure 7. $\mathrm{NH}_{3}$-Temperature Programmed desorption profile for reduced silica-supported copper chromite catalyst.

spectra and are shown in Figure 8. In the case of $\mathrm{SiCuCr} 20$ and $\mathrm{SiCuCr} 30$ catalyst, no distinguished peaks are observed whereas $\mathrm{SiCuCr} 40$ has shown many strong peaks. That means that the catalyst surface is acidic in nature due to which it adsorbed pyridine vapour. The Pyridine adsorbed IR bands near $1605 \mathrm{~cm}^{-1}$ and $1454 \mathrm{~cm}^{-1}$ are assigned to Lewis acid site and the band at $1480 \mathrm{~cm}^{-1}$ indicates both Lewis and Brønsted acid site. ${ }^{41,42}$ The existence of high Lewis acid site on SiCuCr40 compared to SiCuCr30 and $\mathrm{SiCuCr} 20$ seems to influence the conversion of glycerol and also the product distribution. A Brønsted acid will help in eliminating secondary alcohol whereas a Lewis acid more easily coordinates to a primary alcohol thereby weakening the $\mathrm{C}-\mathrm{O} .{ }^{43} \mathrm{In}$ fact, primary alcohol is more reactive than secondary alcohol if a non-acidic condition is applied.

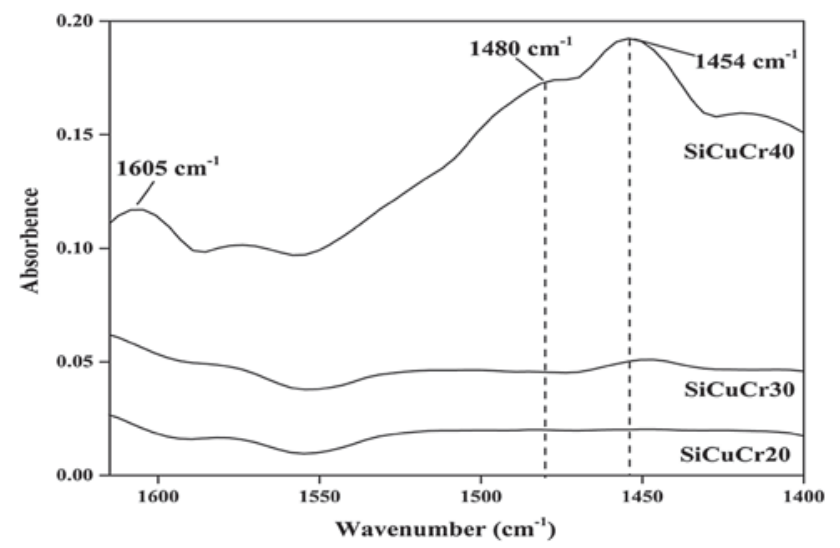

Figure 8. Pyridine IR spectra of reduced silica-supported copper chromite catalyst with different loading.

Acid-catalyzed dehydration of glycerol takes place in two ways. Secondary alcohol dehydration proceeds via a relatively stable intermediate secondary carbocation, which is kinetically controlled. The primary alcohol dehydration via Lewis acid mechanism leads to the formation of acetol, which is the thermodynamically a more stable product. The free energy change in the dehydration reaction of glycerol to 3-hydroxypropyl via secondary alcohol is $-70.2 \mathrm{~kJ} / \mathrm{mol}$ whereas primary alcohol dehydration to acetol is $87.4 \mathrm{~kJ} /$ mole. $^{44}$

\subsection{Catalyst activity test}

Many reactions are happening simultaneously such as dehydration, degradation, polymerization, dehydrogenation, etc. (Scheme 3). The type of reaction depends on many factors such as type of catalyst, reaction temperature, concentration of catalyst, concentration of glycerol, stirring speed, etc. To minimize the effects, we have studied reactions with the same instrument with constant stirring speed. 


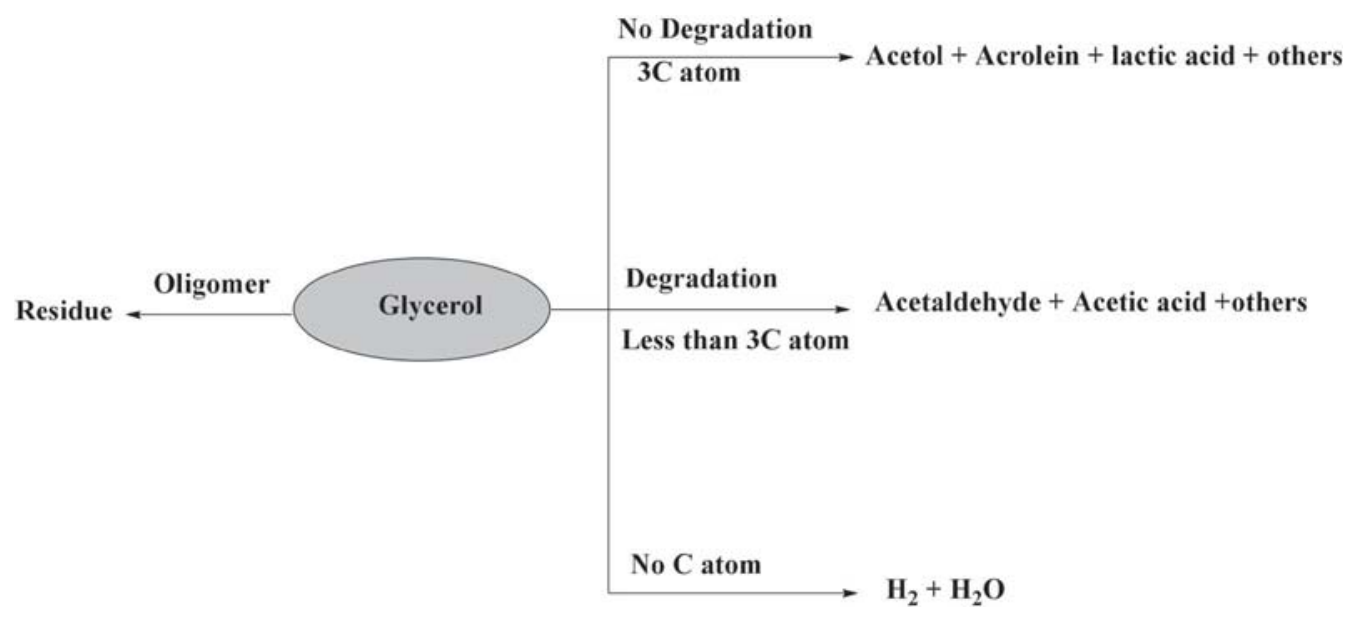

Scheme 3. Reactions of glycerol into different product.

In the glycerol dehydration reaction, four categories of reactions are formed simultaneously. One is oligomerization, which leads to non-volatile products. Second is dehydration, and the others are three carbon atom containing products. ${ }^{45}$ The third is the degradation product which is less than $3 \mathrm{C}$ atoms carbon compounds like acetaldehyde, acetic acid, etc. ${ }^{46}$ The fourth category products are the hydrogen and water which do not contain carbon atom in their molecular structure. ${ }^{47,48}$ Among all the products, one of the dehydration product is acetol (distilled product) which is our prime concern and is used as a reference in analysis.

Dehydration is an endothermic process and proceeds more rapidly at a higher temperature. Glycerol dehydration with silica-supported copper chromite catalyst is studied over three different catalyst sample at $220{ }^{\circ} \mathrm{C}$. The reaction is carried out with $20 \mathrm{vol} \%$ aqueous solution of glycerol with 1 gram of reduced catalyst sample for the duration of $3 \mathrm{~h}$. Figure 9 is the percentage of glycerol conversion and percentage selectivity of distilled product for different silicasupported copper chromite catalyst. Here HPLC technique is used to determine the product compositions. Acetol production is the main product target of our objective. Hence product characterization is compared with reference to acetol yield. The results are shown for three catalyst system as no distilled product is obtained for $\mathrm{SiCuCr10}$. This may be due to the absence of active sites of the catalyst. Glycerol conversion is highest reached $100 \%$ for $\mathrm{SiCuCr} 40$ catalyst and is lowest for SiCuCr30 catalyst. In the case of $30 \mathrm{wt} \%$ catalyst more viscous residue is left after reactions which may be oligomeric products due to which glycerol conversion into distilled product reduces.

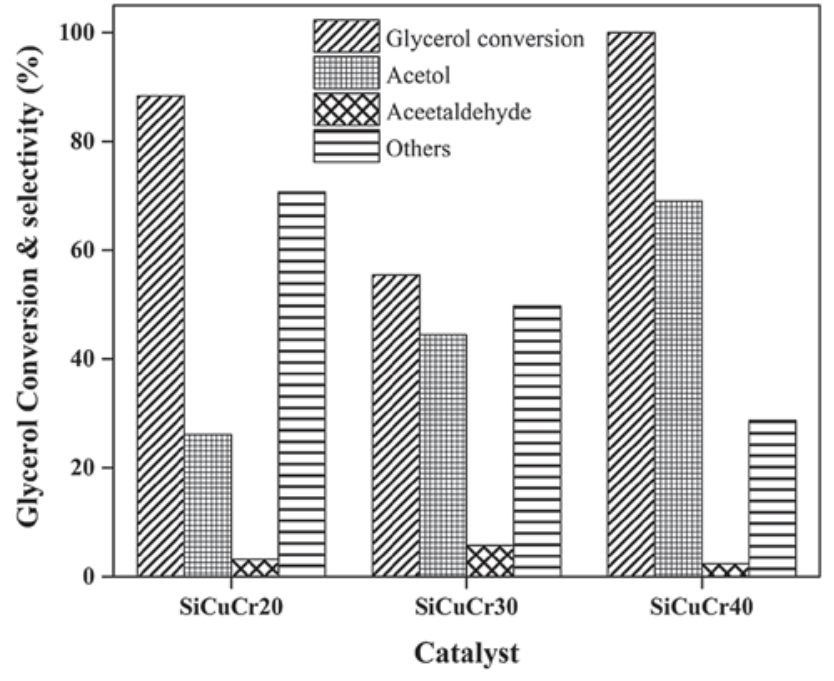

Figure 9. Screening of different silica-supported copper chromite catalyst. Reaction conditions: Glycerol:Water 20:80 (vol\%/vol\%), Reaction temperature $220{ }^{\circ} \mathrm{C}$, Catalyst amount $1 \mathrm{~g}$ and Reaction duration $3 \mathrm{~h}$.

The acetol selectivity increases and is highest for $\mathrm{SiCuCr} 40$ which is near $70 \%$. This is expected as the loading of active compounds (copper chromite) into silica matrix increases more acidic sites generated on the catalyst surface which are responsible for catalytic dehydration. ${ }^{49}$ The selectivity of acetaldehyde is almost similar for the three catalyst system and is below 5\%. But another compound selectivity (byproducts) is highest for $\mathrm{SiCuCr} 20$ which is nearly $70 \%$ and lowest for $\mathrm{SiCuCr} 40$ which is nearly $25 \%$. The lower content of acetol selectivity and formation of by-products with $\mathrm{SiCuCr} 20$ and $\mathrm{SiCuCr} 30$ samples are due to its low content of acidic sites (164 and $234 \mu \mathrm{mol} . \mathrm{g}^{-1}$ respectively) in $\mathrm{NH}_{3}$-TPD and absence of Bronsted and/or Lewis acid sites in the pyridine adsorbed FTIR analysis. At lower loading, by-products 


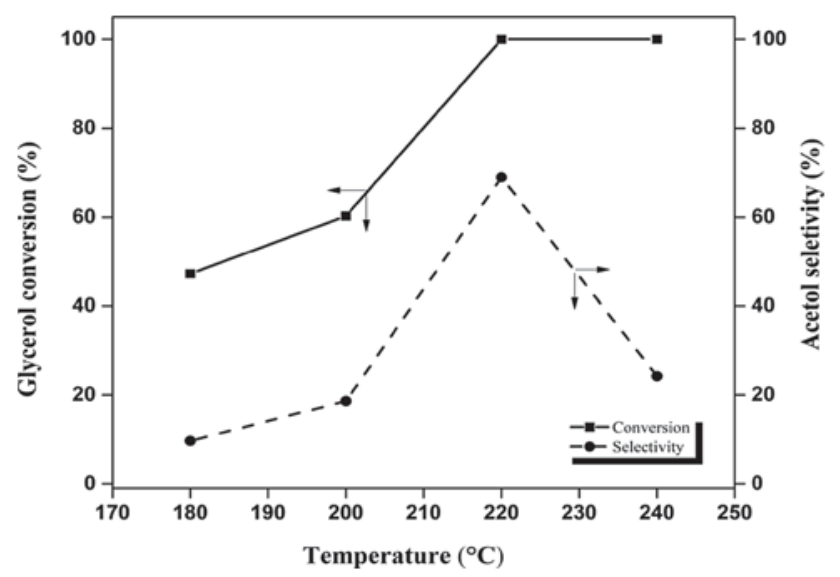

Figure 10. Effect of reaction temperature on $\mathrm{SiCuCr} 40$ catalyst.

are formed in higher amounts because silica support is not fully covered by the copper chromite. When copper chromite loading increases, by-products decrease, and as a result, main product acetol selectivity increases. In lower loading, the reducibility of the catalyst also plays a key role in product selectivity and glycerol conversion. In glycerol dehydration, higher acidic sites of our synthesized catalysts are found to be a crucial part of product selectivity. So $\mathrm{SiCuCr} 40$ is found to be the best catalyst for glycerol dehydration.

3.2a Effect of reaction temperature on catalyst activity: Figure 10 shows the effect of reaction temperature on catalyst activity with $\mathrm{SiCuCr} 40$ in 20 vol\% glycerol solution with 1 gram reduced catalyst for $3 \mathrm{~h}$ in the range of temperature $180-240{ }^{\circ} \mathrm{C}$. ${ }^{4}$

At $180{ }^{\circ} \mathrm{C}$ glycerol conversion is $47 \%$ and it reaches its maximum $(100 \%)$ above $220^{\circ} \mathrm{C}$. At $220^{\circ} \mathrm{C}$ glycerol conversion and acetol selectivity reaches a maximum of $70 \%$ with an increase in temperature. But at $240{ }^{\circ} \mathrm{C}$, acetol selectivity drops drastically from $70 \%$ to $24.2 \%$ due to an increase formation of by-products. ${ }^{50}$ This test indicates that at a higher temperature catalyst favours $\mathrm{C}-\mathrm{C}$ bond cleavage and oxidation is carried out instead of dehydration. This could be promoted by the active phases of the catalyst. ${ }^{9,51}$ The major by-products formed are acetaldehyde due to $\mathrm{C}-\mathrm{C}$ bond cleavage of glycerol and oxidation of acetaldehyde leads to form acetic acid formation. Thus, the high temperature is only favourable for acetol oxidation by $\mathrm{SiCuCr} 40$ catalyst.

$3.2 \mathrm{~b}$ Effect of catalyst amount on catalyst activity: The effect of catalyst loading on the dehydration reaction is studied in the range of $0.5-1.5 \mathrm{~g}$ catalyst at $220^{\circ} \mathrm{C}$ and the results are presented in Figure 11. 20 vol\% glycerol solutions

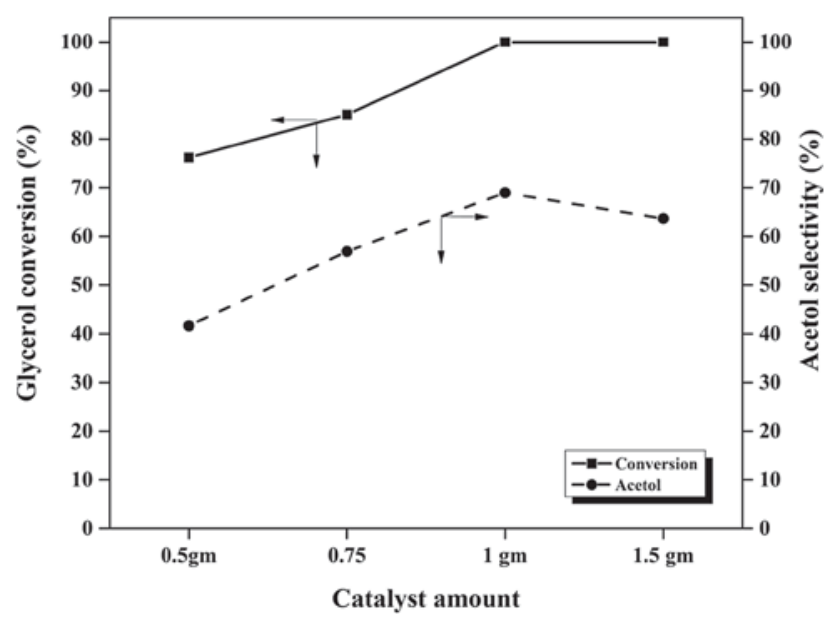

Figure 11. Effect of catalyst amount on SiCuCr40 catalyst.

are used and the reaction is continued up to $3 \mathrm{~h}$ in all cases. It is observed that the conversion of glycerol increased from 76 to $100 \%$ with an increase in catalyst weight from 0.5 to $1.5 \mathrm{~g}$. The selectivity of acetol initially increased from 56 to $70 \%$ for an increase in catalyst weight from 0.5 to $1 \mathrm{~g}$, but after that, it reduces to $63 \%$ for $1.5 \mathrm{gm}$ of catalyst loading. The decrease in acetol product may be due to the formation of side products at higher catalyst loading. The increase in glycerol conversion with increasing catalyst loading could be due to the more available active sites on the catalyst surface for the glycerol dehydration, which leads to excess dehydration to form acetol and lower degraded products.

3.2c Effect of substrate ratio on catalyst activity: The effect of glycerol concentrations on the conversion of glycerol and selectivity pattern is studied in the range of 10-40 vol\% glycerol with $1 \mathrm{~g}$ $\mathrm{SiCuCr} 40$ catalyst at $220^{\circ} \mathrm{C}$ for $3 \mathrm{~h}$ and the results are shown in Figure 12.

The conversion of glycerol remains constant at $100 \%$ while the selectivity of acetol increased from 62 to $69 \%$ with the increase in glycerol concentration from 10-20 vol\%. Interestingly, acetol selectivity decreased from 70 to $35.46 \%$ at $40 \mathrm{vol} \%$ glycerol solution. Acetol selectivity decreases as undesired reaction product may form at high concentration of glycerol aqueous solution. According to Figure 12, the highest selectivity of acetol is obtained at $20 \mathrm{vol} \%$ of glycerol concentration which is found to be the optimum glycerol concentration.

$3.2 \mathrm{~d}$ Effect of reaction time on catalyst activity: The effect of the reaction time on catalyst activity is studied with optimized temperature 


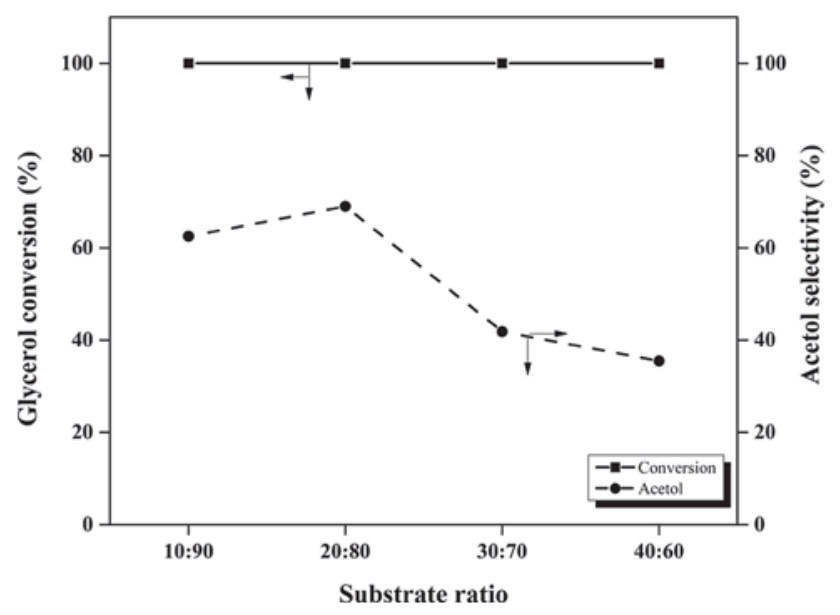

Figure 12. Effect of substrate ratio on $\mathrm{SiCuCr} 40$ catalyst.

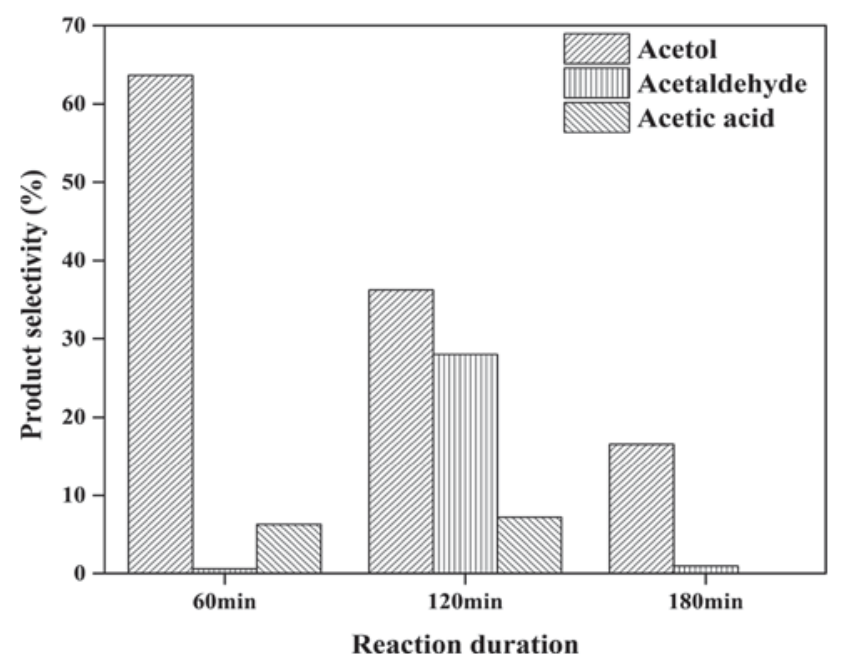

Figure 13. Percentage product selectivity of products after $60 \mathrm{~min}$ interval up to $3 \mathrm{~h}$ reaction time.

$\left(220^{\circ} \mathrm{C}\right)$ for 20 vol\% glycerol concentration with optimized $(1 \mathrm{gm})$ catalyst and the results are shown in Figure 13. Samples are collected after $60 \mathrm{~min}$ interval and are analysed by HPLC. The fractions are collected after reaching the desired reaction temperature. The first fraction $(60 \mathrm{~min})$ shows the highest acetol selectivity $(65 \%)$ which reduces to $35 \%$ in the second fraction and $17 \%$ in the last fraction. Acetic acid selectivity is less than $5 \%$ and is absent in the last fraction. In the second fraction acetaldehyde shows $28 \%$ selectivity. ${ }^{52}$

\subsection{Recycle of the catalyst}

Finally, the catalyst ( $\mathrm{SiCuCr} 40)$ stability is evaluated under optimum conditions. The experiment shows that

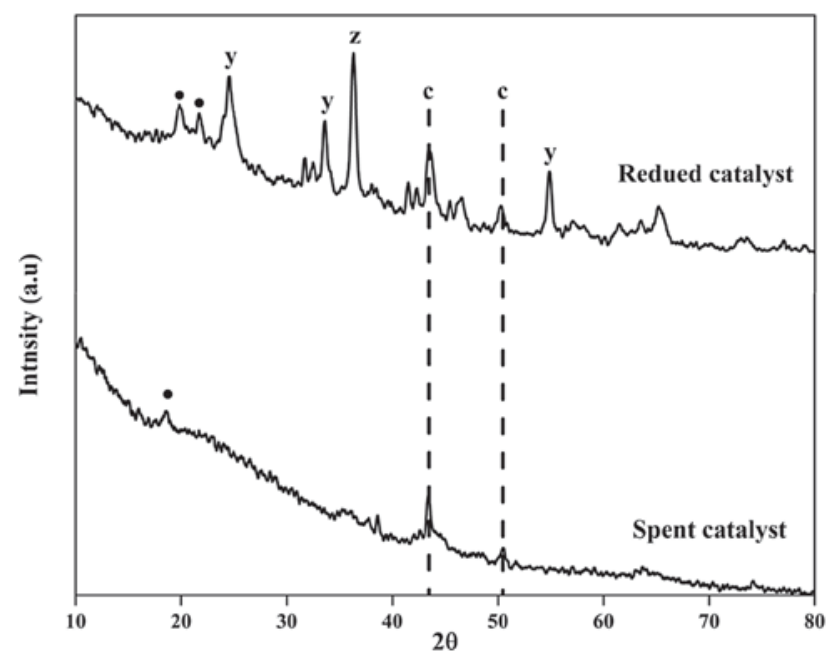

Figure 14. $\mathrm{XRD}$ of reduced and spent catalyst of SiCuCr40 catalyst. (c) $\mathrm{Cu}$, (y) $\mathrm{Cr}_{2} \mathrm{O}_{3}$, (z) Cubic $\mathrm{Cu}_{2} \mathrm{O}$, (ナ) silica.

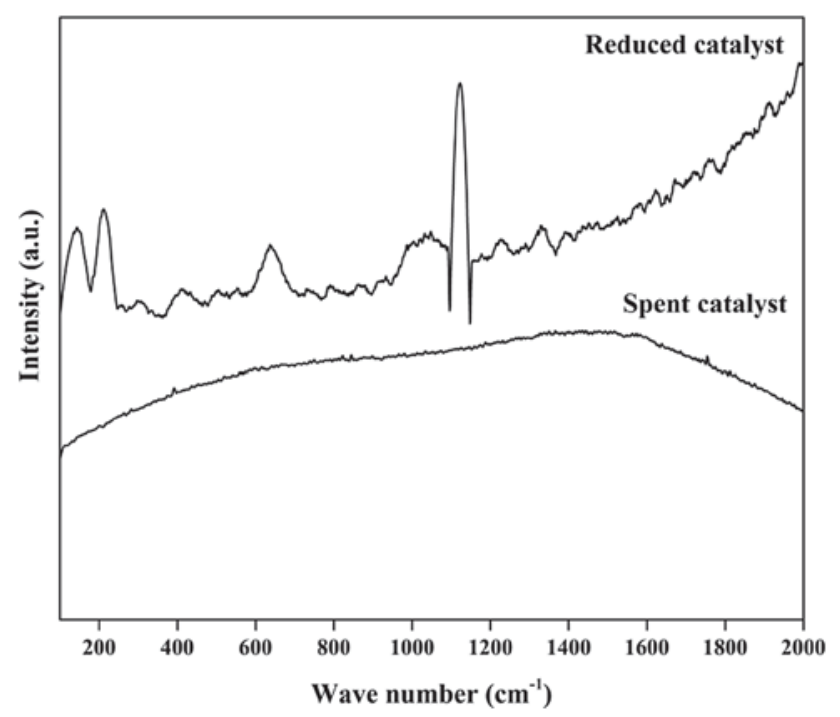

Figure 15. Raman spectroscopy of reduced and spent $\mathrm{SiCuCr} 40$ catalyst.

glycerol conversion decreases from $100 \%$ to $93.3 \%$ whereas the main product acetol selectivity also decreases from $70 \%$ to $19.4 \%$, respectively. The support $\mathrm{SiO}_{2}$ in catalyst $\mathrm{SiCuCr} 40$ is thermally stable but active $\mathrm{Cu}$ has a tendency to lose or agglomerate after each catalytic test. This maybe the reason behind the decrease in the acetol selectivity of the glycerol dehydration. These findings indicate that all catalysts are hydrothermally stable and no coke formation occurs in the reused catalyst based on XRD and Raman spectroscopy.

At the end of the reaction, all the catalysts are recovered, filtered and washed with methanol and dried in a vacuum oven until constant weight. XRD analyses 
of the spent and reduced $\mathrm{SiCuCr} 40$ catalyst are shown in Figure 14. XRD pattern shows that $\mathrm{Cu}_{2} \mathrm{O}(2 \theta=36.4)$ the active compound is absent in spent catalyst through metallic $\mathrm{Cu}(2 \theta=43.4$ and 50.1) is still present. As the active compound $\mathrm{Cu}_{2} \mathrm{O}$ is absent, this will lose its catalytic behaviour. The catalyst should be regenerated after each reaction. In Figure 15 Raman spectroscopy shows that there is no coke formation on the catalyst surface after dehydration reaction.

The oxidised catalyst ( $\mathrm{SiCuCr} 40)$ is used for glycerol dehydration and it gives $23.3 \%$ acetol production with glycerol conversion of $62 \%$. All the above discussion supports the functions of $\mathrm{Cu}^{1+}$ in acetol production. ${ }^{53}$

\section{Conclusions}

Silica-supported copper chromite catalyst were synthesised by acid hydrolysis of sodium silicate. The BET surface area for the synthesized catalyst is maximum for $\mathrm{SiCuCr} 30$ followed by $\mathrm{SiCuCr} 40$. The elemental mapping shows even distribution of copper and chromium throughout the catalyst. EDX result showed the increasing atomic percentage of copper and chromium with an increasing amount of loading. XRD spectra of calcined catalyst showed the tetragonal spinal structure of $\mathrm{CuCr}_{2} \mathrm{O}_{4}$ and monoclinic $\mathrm{CuO}$. XRD spectra of reduced catalyst showed the presence of $\mathrm{Cu}^{0}, \mathrm{Cu}^{+1}$ and $\mathrm{Cr}_{2} \mathrm{O}_{3}$. The reducing temperature was $350{ }^{\circ} \mathrm{C}$ determined by $\mathrm{H}_{2}$-TPR analysis where $\mathrm{Cu}^{+2}$ ion converted to $\mathrm{Cu}^{+1}$ ion. The highest amount of acidic sites $\left(1250 \mu \mathrm{mol} . \mathrm{g}^{-1}\right)$ was obtained for (SiCuCr40) $40 \mathrm{wt} \%$ catalyst in $\mathrm{NH}_{3}$-TPD studies. Pyridine adsorption FTIR showed strong Lewis acid sites for reduced catalysts. Cuprous oxide which acts as Lewis acid sites on catalyst surface was responsible for high acetol selectivity in glycerol dehydration. Glycerol dehydration was carried out with four different catalysts at different temperatures. The optimized reaction temperature was $220^{\circ} \mathrm{C}$ for $3 \mathrm{~h}$ with 1 gm catalyst and $20 \mathrm{vol} \%$ aqueous glycerol solution for $3 \mathrm{~h}$. SiCuCr40 showed the highest acetol selectivity (70\%) and nearly $100 \%$ glycerol conversion. The XRD analysis of the spent catalyst showed the presence of copper metal but the absence of $\mathrm{Cu}^{+1}$ ion indicates the loss of activity after the reaction. The calcined $\mathrm{SiCuCr} 40$ catalyst (oxidised form) showed $23.3 \%$ acetol selectivity and low glycerol conversion $62 \%$. Spent $\mathrm{SiCuCr} 40$ catalyst also showed low acetol selectivity $(19.4 \%)$ with $93.3 \%$ glycerol conversion. Hence, cuprous ion is the reason for high acetol selectivity for glycerol conversion.

\section{Acknowledgement}

The authors gratefully acknowledge the state of the art testing facility at Central Instrumentation Facility of Birla Institute of Technology Mesra.

\section{References}

1. Kong P S, Kheireddine M, Mohd W and Wan A 2016 Conversion of crude and pure glycerol into derivatives: A feasibility evaluation Renew. Sustain. Energy Rev. 63 533

2. Meher L C, Dharmagadda V S S and Naik S N 2006 Optimization of alkali-catalyzed transesterification of Pongamia pinnata oil for production of biodiesel Bioresour. Technol. 971392

3. Xiao Z, Li C, Xiu J, Wang X, Williams C T and Liang C 2012 Chemical Insights into the reaction pathways of glycerol hydrogenolysis over $\mathrm{Cu}-\mathrm{Cr}$ catalysts $\mathrm{J}$. Mol. Catal. A Chem. 36524

4. Yue C J, Gan M M, Gu L P and Zhuang Y F 2014 In situ synthesized nano-copper over ZSM-5 for the catalytic dehydration of glycerol under mild conditions J. Taiwan Inst. Chem. Eng. 451443

5. Magar S, Kamble S, Mohanraj G T, Jana S K and Rode C 2017 Solid-acid-catalyzed etherification of glycerol to potential fuel additives Energy Fuels 311227

6. Behr A 2008 The future of glycerol. New usages for a versatile raw material. By Mario Pagliaro and Michele Rossi ChemSusChem 1653

7. Pagliaro M, Ciriminna R, Kimura H, Rossi M and Della Pina C 2007 From glycerol to value-added products Angew. Chem. Int. Ed. $\mathbf{4 6} 4434$

8. Suthagar K, Shanthi K and Selvam P 2018 Hydrogenolysis of glycerol over silica-supported copper-nanocatalyst: Effect of precipitating-agent and copper metal-loading Mol. Catal. 458307

9. Dasari M A, Kiatsimkul P P, Sutterlin W R and Suppes G J 2005 Low-pressure hydrogenolysis of glycerol to propylene glycol Appl. Catal. A Gen. 281225

10. Liang C, Ma Z and Ding L 2009 template preparation of highly active and selective $\mathrm{Cu}-\mathrm{Cr}$ catalysts with high surface area for glycerol hydrogenolysis Catal. Lett. 130169

11. Huang Z, Cui F, Kang H, Chen J, Zhang X and Xia C 2008 Highly dispersed silica-supported copper nanoparticles prepared by precipitation-Gel Method: A Simple but Efficient and Stable Catalyst for Glycerol Hydrogenolysis Chem. Mater. 205090

12. Kim N D, Oh S, Joo JB, Jung K S and Yi J 2010 The promotion effect of $\mathrm{Cr}$ on copper catalyst in hydrogenolysis of glycerol to propylene glycol Top. Catal. 53517

13. Rode C V, Ghalwadkar A A, Mane R B, Hengne A M, Jadkar S T and Biradar N S 2010 Selective hydrogenolysis of glycerol to 1,2-propanediol: Comparison of batch and continuous process operations Org. Process Res. Dev. 141385

14. Pantaleo G, Liotta L F, Venezia A M, Deganello G, Ezzo E M, El Kherbawi M A and Atia H 2009 Support effect on the structure and $\mathrm{CO}$ oxidation activity of $\mathrm{Cu}$ - 
$\mathrm{Cr}$ mixed oxides over $\mathrm{Al}_{2} \mathrm{O}_{3}$ and $\mathrm{SiO}_{2}$ Mater. Chem. Phys. 114604

15. Sato S, Akiyama M, Takahashi R, Hara T, Inui K and Yokota M 2008 Vapor-phase reaction of polyols over copper catalysts Appl. Catal. A Gen. 347186

16. Chiu C-W, Dasari M A, Suppes G J and Sutterlin W R 2005 Dehydration of glycerol to acetol via catalytic reactive distillation AIChE J. 523543

17. Braga T P, Pinheiro A N, Teixeira C V and Valentini A 2009 Dehydrogenation of ethylbenzene in the presence of $\mathrm{CO}_{2}$ using a catalyst synthesized by polymeric precursor method Appl. Catal. A Gen. 366193

18. Vasiliadou E S and Lemonidou A A 2011 Investigating the performance and deactivation behaviour of silicasupported copper catalysts in glycerol hydrogenolysis Appl. Catal. A Gen. 396177

19. Miyazawa T, Kusunoki Y, Kunimori K and Tomishige K 2006 Glycerol conversion in the aqueous solution under hydrogen over $\mathrm{Ru} / \mathrm{C}+$ an ion-exchange resin and its reaction mechanism J. Catal. 240213

20. Chaminand J, Djakovitch LA, Gallezot P, Marion P, Pinel C and Rosier C 2004 Glycerol hydrogenolysis on heterogeneous catalysts Green Chem. 6359

21. Li K T, Li J Y and Li H H 2017 Conversion of glycerol to lactic acid over $\mathrm{Cu}-\mathrm{Zn}-\mathrm{Al}$ and $\mathrm{Cu}-\mathrm{Cr}$ catalysts in alkaline solution J. Taiwan Inst. Chem. Eng. 7974

22. Suprun W, Lutecki M, Haber T and Papp H 2009 Acidic catalysts for the dehydration of glycerol: Activity and deactivation J. Mol. Catal. A Chem. 309 71

23. Shree V and Sen A K 2018 Study of thermal and flame behavior of phosphorus-based silica for epoxy composites J. Sol-Gel. Sci. Technol. 85269

24. Mane R B and Rode C V 2012 Continuous dehydration and hydrogenolysis of glycerol over non-chromium copper catalyst: Laboratory-scale process studies Org. Process. Res. Dev. 161043

25. Raksaphort S, Pengpanich S and Hunsom M 2014 Products Distribution of glycerol hydrogenolysis over supported co catalysts in a liquid phase Kinet. Catal. 55 456

26. Hao S, Peng $\mathrm{W}$, Zhao $\mathrm{N}$ and Xiao F 2010 Hydrogenolysis of glycerol to 1,2-propanediol catalyzed by $\mathrm{Cu}-\mathrm{H}_{4} \mathrm{SiW}_{12} \mathrm{O}_{40} / \mathrm{Al}_{2} \mathrm{O}_{3}$ in liquid J. Chem. Tech. Biotech. 851499

27. Vankudoth K, Gutta N, Velisoju V K, Mutyala S, Aytam $\mathrm{H} \mathrm{P}$ and Akula V $2017 \mathrm{CuCr}_{2} \mathrm{O}_{4}$ derived by the sol-gel method as a highly active and selective catalyst for the conversion of glycerol to 2,6-dimethylpyrazine: A benign and eco-friendly process Catal. Sci. Technol. 73399

28. Kinage A K, Upare P P, Kasinathan P, Hwang Y K and Chang J S 2010 Selective conversion of glycerol to acetol over sodium-doped metal oxide catalysts Catal. Commun. 11620

29. Zhang B, Hui S, Zhang S, Ji Y, Li W and Fang D 2012 Effect of copper loading on texture, structure and catalytic performance of $\mathrm{Cu} / \mathrm{SiO}_{2}$ catalyst for hydrogenation of dimethyl oxalate to ethylene glycol J. Nat. Gas Chem. 21563

30. Mobini S, Meshkani F and Rezaei M 2017 Surfactantassisted hydrothermal synthesis of $\mathrm{CuCr}_{2} \mathrm{O}_{4}$ spinel catalyst and its application in CO oxidation process $J$. Environ. Chem. Eng. 54906

31. Santacesaria E, Carotenuto G, Tesser R and Di Serio M 2012 Ethanol dehydrogenation to ethyl acetate by using copper and copper chromite catalysts Chem. Eng. J. 179209

32. Hosseini S G, Abazari R and Gavi A 2014 Pure $\mathrm{CuCr}_{2} \mathrm{O}_{4}$ nanoparticles: Synthesis, characterization and their morphological and size effects on the catalytic thermal decomposition of ammonium perchlorate Solid State Sci. 3772

33. Khasin A A, Yur'eva T M, Plyasova L M, Kustova G N, Jobic H, Ivanov A, Chesalov Y A, Zaikovskii V I, Khasin A V, Davydova L P and Parmon V N 2008 Mechanistic features of reduction of copper chromite and state of absorbed hydrogen in the structure of reduced copper chromite Russ. J. Gen. Chem. 782203

34. Kawamoto A M, Pardini L C and Rezende L C 2004 Synthesis of copper chromite catalyst Aerosp. Sci. Technol. 8591

35. Luo M-F, Zhong Y-J, Yuan X-X and Zheng X-M 1997 TPR and TPD studies of $\mathrm{CuOCeO}_{2}$ catalysts for low temperature CO oxidation Appl. Catal. A Gen. 162121

36. Xiao Z, Wang X, Xiu J, Wang Y, Williams C T and Liang C 2014 Synergetic effect between $\mathrm{Cu}^{0}$ and $\mathrm{Cu}{ }^{+}$ in the $\mathrm{Cu}-\mathrm{Cr}$ catalysts for hydrogenolysis of glycerol Catal. Today 234200

37. Braga T P, Essayem N and Valentini A 2017 Correlation between the basicity of $\mathrm{Cu}-\mathrm{MxOy}-\mathrm{Al}_{2} \mathrm{O}_{3}(-$ $\mathrm{M}=\mathrm{Ba}, \mathrm{Mg}, \mathrm{K}$ or $\mathrm{La})$ oxide and the catalytic performance in the glycerol conversion from adsorption microcalorimetry characterization J. Therm. Anal. Calorim. 12965

38. Célerier S, Morisset S, Batonneau-gener I, Belin T, Younes K and Batiot-dupeyrat C 2018 Glycerol dehydration to hydroxyacetone in gas phase over copper supported on magnesium oxide(hydroxide)fluoride catalysts Appl. Catal. A Gen. 557135

39. Tendam J and Hanefeld U 2011 Renewable chemicals: Dehydroxylation of glycerol and polyols ChemSusChem 41017

40. Rodríguez-González L, Hermes F, Bertmer M, Rodríguez-Castellón E, Jiménez-López A and Simon U 2007 The acid properties of H-ZSM-5 as studied by $\mathrm{NH}_{3}-$ TPD and 27Al-MAS-NMR spectroscopy Appl. Catal. A Gen. 328174

41. Krishna V, Naresh G, Kumar V V, Sarkari R, Padmasri A H and Venugopal A 2016 Synthesis of 2,6-dimethylpyrazine by dehydrocyclization of aqueous glycerol and 1,2-propanediamine over $\mathrm{CuCrO}$ catalyst: Rationalization of active sites by pyridine and formic acid adsorbed IR studies Appl. Catal. B Environ. 19358

42. Stošić D, Bennici S, Sirotin S, Stelmachowski P, Couturier J L, Dubois J L, Travert A and Auroux A 2014 Examination of acid-base properties of solid catalysts for gas phase dehydration of glycerol: FTIR and adsorption microcalorimetry studies Catal. Today 226167

43. Alhanash A, Kozhevnikova E F and Kozhevnikov I V 2010 Gas-phase dehydration of glycerol to acrolein catalysed by caesium heteropoly salt Appl. Catal. A Gen. 37811 
44. Nimlos M R, Blanksby S J, Qian X, Himmel M E and Johnson D K 2006 Mechanisms of glycerol dehydration J. Phys. Chem. A 1106145

45. Martin A and Richter M 2011 Oligomerization of glycerol - a critical review Eur. J. Lipid Sci. Technol. 113100

46. de Sousa F F, Campos A, Filho E C da S, Millet E R C, Pinheiro L G, Carvalho D C, Fonseca M G, Filho J M, Oliveira A C and Saraiva G D 2013 Characterization and catalytic performances of copper and cobalt-exchanged hydroxyapatite in glycerol conversion for 1-hydroxyacetone production Appl. Catal. A Gen. 47139

47. Goula M A, Charisiou N D, Pandis P K and Stathopoulos V N 2016 A Ni/apatite-type lanthanum silicate supported catalyst in glycerol steam reforming reaction $R S C A d v .678954$

48. Iriondo A, Barrio V L, Cambra J F, Arias P L, Guemez M B, Sanchez-Sanchez M C, Navarro R M and Fierro J L G 2010 Glycerol steam reforming over Ni catalysts supported on ceria and ceria-promoted alumina Int. J. Hydrogen Energy 3511622

49. Sad M E, Duarte H A, Vignatti C, Padró C L and Apesteguía C R 2015 Steam reforming of glycerol:
Hydrogen production optimization Int. J. Hydrogen Energy 406097

50. Mane R B, Yamaguchi A, Malawadkar A, Shirai M and Rode C V 2013 Active sites in modified copper catalysts for selective liquid phase dehydration of aqueous glycerol to acetol $R S C A d v .316499$

51. Davda R R, Shabaker J W, Huber G W, Cortright R D and Dumesic J A 2005 A review of catalytic issues and process conditions for renewable hydrogen and alkanes by aqueous-phase reforming of oxygenated hydrocarbons over supported metal catalysts Appl. Catal. $B$ Environ. 56171

52. Braga T P, Essayem N, Prakash S and Valentini A 2016 Gas-Phase conversion of glycerol to acetol: Influence of support acidity on the catalytic stability and copper surface properties on the activity J. Braz. Chem. Soc. 272361

53. Torresi P A, Díez V K, Luggren P J and Di Cosimo J I 2013 Conversion of diols by dehydrogenation and dehydration reactions on silica-supported copper catalysts Appl. Catal. A Gen. 458119 